DOI 10. 18307/2018. 0105

(C) 2018 by Journal of Lake Sciences

\title{
基于农户个体行为的珠江流域氮、磷营养盐控制政策情景分析“
}

\author{
徐 鹏 $^{1}$, 林永红 ${ }^{2}$, 郑君倢 ${ }^{2}$,杨顺顺 ${ }^{3}$, 栾胜基 ${ }^{1,2}$ ** \\ (1: 北京大学环境科学与工程学院, 北京 100871) \\ ( 2 : 北京大学深圳研究生院环境与能源学院, 深圳 518055$)$ \\ (3:湖南省社会科学院, 长沙 410003)
}

\begin{abstract}
摘 要: 为揭示农户个体行为与流域农业非点源营养盐产生和控制政策之间的逻辑关系, 以珠江流域为研究对象,采用 系统动力学模型与多主体农户和农村环境管理模型耦合构建流域营养盐污染控制政策的情景分析方法, 基于农户在化 肥税和农药税组合型政策下的生产行为设计了基准情景、低化肥税情景、中化肥税情景和高化肥税情景 4 种具有代表性 的情景方案,并在各种情景下定量描述流域营养盐对农业政策的响应和评估流域营养盐控制的优选政策方案. 结果显 示: 从农业投人和产出的角度看,2030 年低化肥税情景、中化肥税情景和高化肥税情景的化肥施用量相对基准情景分别 减少了 $24.0 \%$ 、 $39.8 \%$ 和 $50.2 \%$, 农药使用量分别减少了 $27.6 \%$ 、 $32.8 \%$ 和 $37.4 \%$, 农作物产量分别减少了 $10.0 \% 、 16.3 \%$ 和 $21.2 \%$, 畜禽养殖量分别增加了 $5.9 \% 、 7.5 \%$ 和 $14.0 \%$; 2030 年, 基准情景、低化肥税情景、中化肥税情景和高化肥税情景的 总氮人河量分别达到 $94.5 、 85.1$ 、78.5 和 75.3 万 $\mathrm{t}$, 总磷人河量分别达到 $14.0 、 12.8 、 12.0$ 和 11.6 万 $\mathrm{t}$; 化肥税和农药税的组 合型政策能够有效减少营养盐污染量, 然而, 中化肥税情景和高化肥税情景比低化肥税情景的边际效果小、经济成本高、 农作物产出低和畜禽污染高,故低化肥税情景被认为是控制珠江流域营养盐污染的最优方案.
\end{abstract}

关键词: 珠江流域;营养盐;税收政策;农业面源;营养盐控制;化肥;总氮;总磷

\section{Policies scenario analysis based on the farmers' individual behavior for nitrogen and phosphorous nutrient controlling of Pearl River Basin}

\author{
XU Peng ${ }^{1}$, LIN Yonghong ${ }^{2}$, ZHENG Junjie ${ }^{2}$, YANG Shunshun ${ }^{3} \&$ LUAN Shengji $^{1,2 * *}$ \\ (1: College of Environmental Sciences and Engineering, Peking University, Beijing 100871, P.R.China) \\ (2: School of Environment and Energy, Shenzhen Graduate School, Peking University, Shenzhen 518055, P.R.China) \\ (3: Hunan Academy of Social Sciences, Changsha 410003, P.R.China)
}

Abstract: To reveal the logical relationship between farmers' individual behavior and the generation and control policies of agricultural non-point source nutrient in watershed, scenario analysis approaches in watershed nutrient control policies are established based on coupling System Dynamic model with Multi-agent Agricultural household model for Rural Environmental Management model. This research took Pearl River Basin as the research object. This study designs four future scenarios: business-as-usual scenario, low fertilizer fax rate scenario, middle fertilizer fax rate scenario and high fertilizer fax rate scenario, simultaneously with the same pesticide tax rate of $25 \%$ for latter three policy scenarios. Under various scenarios, the response of watershed nutrient to agricultural policies is quantitatively described and optimal policy for controlling watershed nutrient is assessed. The results indicate that in low fertilizer fax rate scenario, middle fertilizer fax rate scenario and high fertilizer fax rate scenario for 2030, the quantity of synthetic fertilizer applied will be $24.0 \%, 39.8 \%$ and $50.2 \%$ less than that of in business-as-usual scenario, respectively; the quantity of pesticide applied will be $27.6 \%, 32.8 \%$ and $37.4 \%$ less than that of in business-as-usual scenario, respectively; crop yield will be $10.0 \%, 16.3 \%$ and $21.2 \%$ less than that of in business-as-usual scenario, respectively; the number of livestock will be $5.9 \%, 7.5 \%$ and $14.0 \%$ higher than that of in business-as-usual scenario, respectively. In business-as-usual scenario, low fer-

* 国际科技合作专项 (2012DFG92020)、湖南省哲学社会科学基金项目 (13YBB139) 和湖南省自然科学基金项目 (2015JJ3083) 联合资助. 2016-12-08 收稿; 2017-04-10 收修改稿. 徐鹏 (1989 ), 男, 博士研究生; E-mail: xupenglzl@ pku.edu.cn. 林永红(1990 ),并列第一作者,女,硕士研究生; E-mail: syhlin@ 163.com.

** 通信作者; E-mail: luansj@ pkusz.edu.cn. 
tilizer fax rate scenario, middle fertilizer fax rate scenario and high fertilizer fax rate scenario for 2030, the total nitrogen input to Pearl River Basin will be $9.45 \times 10^{5}, 8.51 \times 10^{5}, 7.85 \times 10^{5}$ and $7.53 \times 10^{5} \mathrm{t}$, respectively; the total phosphorus input to Pearl River Basin will be $1.40 \times 10^{5}, 1.28 \times 10^{5}, 1.20 \times 10^{5}$ and $1.16 \times 10^{5} \mathrm{t}$. The combination of fertilizer tax rate and pesticide tax rate can effectively reduce the discharge of nutrient. Even though middle fertilizer fax rate scenario and high fertilizer fax rate scenario have greater control effects, they have marginal effect, higher economic cost, less crop production and more animal manure pollution compared to low fertilizer fax rate scenario. Therefore, the policy option carried out in low fertilizer fax rate scenario is considered to be optimal for controlling Pearl River's nutrient pollution.

Keywords: Pearl River Basin; nutrient; fax policy; agricultural non-point source; nutrient control; fertilizers; total nitrogen; total phosphorus

自 1970s 改革开放以来, 珠江流域氮、磷营养盐向沿海水域输出的趋势显著升高, 致使珠江口富营养化 加剧, 赤潮发生频率增加且持续时间延长, 水体底层缺氧或低氧, 以及生物多样性减少等, 对河口及近海海 域生态环境造成了严重负面影响 ${ }^{[1-4]}$. 农业非点源受农户生产行为、农业管理措施和农业政策等因素的影 响 ${ }^{[5-6]}$, 其造成的珠江流域营养盐输出是珠江口及近海水域营养物质的主要来源 ${ }^{[7-9]}$, 农业非点源营养盐污 染控制决定了流域营养盐污染管理能否取得成效 ${ }^{[10-12]}$. 因此, 将农户作为农村环境管理主体, 从农户个体行 为角度来探讨农业非点源营养盐污染的产生与控制政策, 从根本上来降低流域营养盐污染.

然而, 在研究流域营养盐污染问题上, 已有的报道大多利用 Global NEWS ( Nutrient Export from WaterSheds) 模型模拟过去、现在及未来不同阶段全球或区域范围内不同形态营养盐从流域向近海输出变化情 况 ${ }^{[13-17]}$. 此外, 一些基于动态过程的模型也用于流域营养盐模拟, 如 HSPF ( Hydrologic Simulation ProgramFortran) ${ }^{[18]}$ 、AnnAGNPS ( Annualized Agricultural Nonpoint Source) ${ }^{[19]}$ 和 SWAT (Soil and Water Assessment Tool $)^{[20-21]}$ 等. 除了利用模型模拟流域营养盐污染问题外,国内外学者还关注农业政策对营养盐污染的调控 作用. 事实上, 美国和欧洲自 1990s 初期就通过实施 10\% 30\%的化肥税或农药税来鼓励环境友好型农

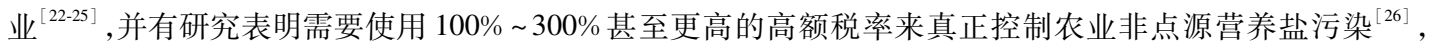
但高额税率会给农户收人造成不利影响. 在中国, 主要通过实施补贴政策来控制农业非点源营养盐污 染 ${ }^{[27]}$, 鲜有研究通过税收政策调控实现流域营养盐污染控制. 基于以上研究, 本文认为还有以下几个方面 需要加强: (1)未能重视农户行为微观层面对流域营养盐污染宏观层面的影响, 较少结合政策管理模型来模 拟营养盐污染控制效果; 2) 一些模型由于是全球尺度和输人参数多基于国外数据, 无法很好地适用于我国 特定区域的营养盐污染控制和管理研究领域; (3)部分模型需要数据量大且一些参数难以获取等造成输出结 果不确定性增加; (4)未能全面的描述我国农业非点源污染产生的关键过程, 如农户施肥、灌溉、收割、堆肥、 沼气处理、污水收集等.

本研究针对农户生产决策引起的农业营养盐污染, 联用系统动力学 (System Dynamics, SD) 模型与多主 体农户和农村环境管理模型 (multi-agent agricultural household model for rural environmental management, MAREM) 构建流域营养盐污染控制政策的情景分析方法, 关注农业非点源营养盐污染, 定量描述农户个体 行为与流域农业非点源营养盐产生和控制政策之间的逻辑关系, 以珠江流域为例, 基于农户在化肥税和农 药税组合型政策下的生产行为进行情景模拟, 并在不同情景下对 2013-2030 年珠江各大支流进人干流的 氮、磷营养盐 (即人河量) 进行预测, 定量描述流域营养盐污染对农业政策的响应和评估流域营养盐控制的 优选政策方案,为我国流域水质管理和富营养化控制提供科学依据.

\section{1 材料与方法}

本研究从农户个体行为角度出发, 联用 MAREM 模型和流域营养盐污染 SD 仿真模型构建了珠江流域营 养盐污染的农业控制政策情景分析框架(图 1). 在本研究中,利用 SD 模型构建了以农业生产污染子系统为核 心的流域营养盐污染仿真系统, 其中农业生产污染子系统的农作物生产部分是依据 Cobb-Douglas(C-D) 生产 函数来建立的, 仿真系统的历史数据来源、生产要素构成和函数内的相应参数均与 MAREM 系统中农户生 产子系统内的一致,这是实现两个系统连接以及农业政策对营养盐污染控制情景模拟的基础. MAREM 模型 能够进行农业政策的情景分析, 并获得相应政策情景下经过自适应调整后农户对化肥、农药等生产要素投 
人的决策行为以及种植、养殖生产行为的互动过程及其数据, 而这些生产投人正是影响农业营养盐污染状 况的关键变量, 因此可以把 MAREM 模型进行政策情景模拟后输出的生产数据作为农业污染子系统的输人 数据, 然后利用 SD 仿真系统量化农户生产行为改变后的农业营养盐污染量以及总污染量的变化,并据此评 估不同农业政策对流域营养盐污染的控制作用. SD 仿真模型及参数选取参考文献 [28].

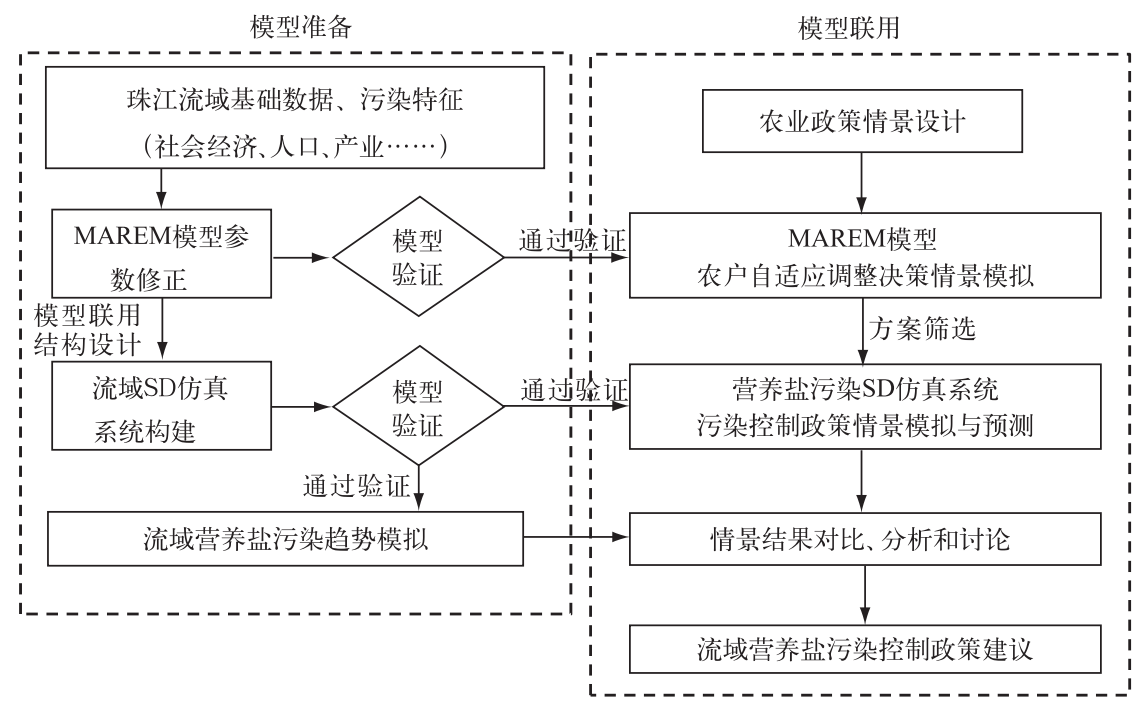

图 1 珠江流域营养盐污染的农业控制政策情景分析框架

Fig. 1 The structure of agricultural control policies scenario analysis in Pearl River Basin nutrient pollution

\subsection{MAREM 模型}

本研究涉及的 MAREM 模型是由杨顺顺等利用仿真平台 Swam 和 Java 语言开发的一套用于模拟特定农 业政策下农户的生产、消费、劳动力供给决策行为以及由此带来的农村环境变化的系统 ${ }^{[29]}$. 系统设计了一 个 $60 \times 60$ 网格大小的人工村落 (每一个网格映射现实世界里的 1 亩地, 即 $1 / 15 \mathrm{hm}^{2}$ ), 村落中共有 200 户农 户生活,每户农户在成员数、贫富程度、年龄、受教育程度、风险偏好等特征上有所不同, 这些属性对农户的 决策有所影响. 此外系统还设计了政府、非农就业市场、农资企业等多类主体. 它们的共同特征是均通过其 在系统中具有的 “功能”或者 “职能” 来体现它们的存在而不在系统中拥有实体并占据网格空间,而它们所 执行的任务表现为政府实施的针对农户的农业补贴或税收政策,引导农户生产、影响劳动力转移或土地流 转的政策,市场调整下的农产品价格变化或波动等现象. 该模型已多次实现基于农户微观尺度的化肥税和 环境服务付费的政策模拟应用研究 ${ }^{[6,30-31]}$.

1.1.1 模型结构及参数设置 MAREM 模型由农户生产、农户消费、社会环境和农村环境评估 4 个子系统组 成; 内含多个可供调整的参数, 包括世界大小及投放农户的数量、模型运行模式 (政策情景设置)、农户规模 化养殖的能力、与非农部门就业有关的参数、C-D 生产函数的各种效率变量和要素产出弹性、与环境评估系 统中使用的模型或排放系数有关的参数等. 系统的时间单位就是仿真时间单位, 或者称之为步 (step), 是一 个虚拟时间; 而农户的从业选择、生产和消费都是以年为周期做出的, 故每一个仿真步长都映射现实世界里 的一年(但虚拟时间和现实时间不完全对等, 模型中设计农户对每一步生产要素的调整较现实世界的每一 年的幅度要更细微, 因此若干步可大致相当于现实中的一年). 在本研究中, 为了实现 SD 模型和 MAREM 模 型耦合, 还需要建立它们共用的 C-D 生产函数和相同的模拟起始点. 杨顺顺设计的 MAREM 模型中模拟的 起点大致相当于我国 1990s 初的情况, 各类参数也按照当时的情况或根据目前的数据进行反推得到 ${ }^{[29]}$, 即 各个要素的取值使用的是全国平均值. 因此在将 MAREM 模型应用到珠江流域时, 需要根据珠江流域的实 际情况, 对模型与流域营养盐污染 SD 仿真系统的连接部分, 即农户生产子系统的相关参数进行调整和率 定, 使得模型的仿真结果与实际数据吻合. 本研究对化肥税和农药税两类政策进行情景模拟, 主要涉及模型 
中农户生产子系统的种植业部分, 设置的参数主要包括农户属性 (年龄段和受教育程度)、生产要素的产出 弹性系数、生产要素的初始值调整和政策情景分析初始步数调整, 其余参数设置过程和取值参考文献 [29], MAREM 模拟程序和计算模板等可以联系作者来获取.

农户生产子系统基于中国主要农作物的产品总量和结构数据, 设计了一种虚拟作物, 同时使用 C-D 生 产函数来表达主要农作物的生产投人和产品产出之间的关系,具体公式为:

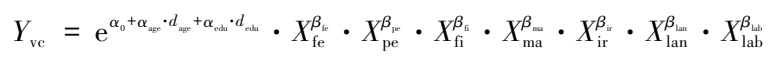

式中, $Y_{\mathrm{vc}}$ 为虚拟作物产量, $X_{\mathrm{fe}} 、 X_{\mathrm{pe}} 、 X_{\mathrm{fi}} 、 X_{\mathrm{ma}} 、 X_{\mathrm{ir}} 、 X_{\mathrm{lan}}$ 和 $X_{\mathrm{lab}}$ 分别为化肥、农药、农地膜、机械、灌溉 (比例)、土 地、劳动力 7 种要素的投人量, $\beta_{\mathrm{fe}}, \beta_{\mathrm{pe}}, \beta_{\mathrm{fi}}, \beta_{\mathrm{ma}}, \beta_{\mathrm{ir}}, \beta_{\mathrm{lan}}$ 和 $\beta_{\mathrm{lab}}$ 分别为这 7 种要素的产出弹性系数, $d_{\mathrm{age}}$ 和 $d_{\mathrm{edu}}$ 分 别为农户的年龄段和受教育程度, $\alpha_{\mathrm{ege}}$ 和 $\alpha_{\text {edu }}$ 则为这两个属性的效率变量, $\alpha_{0}$ 为回归常数.

本研究中, 首先利用 2000 年珠江流域的化肥施用强度、农药施用强度、农用薄膜使用强度、机械总动力 强度、灌溉比例、耕地面积和劳动力投人强度数据来修正模型中各生产要素的初始值. 在农户属性参数设置 中, 根据农户访谈结果确定 ${ }^{[32-33]}$, 珠江流域从事农业生产的农户年龄段主要为 $41 \sim 50$ 岁 (取值范围为 $1 \sim 5$, 30 岁及以下、31 40 岁、41 50 岁、51 60 岁和 60 岁以上在生产函数中分别赋值 $2 、 4 、 5 、 4 、 3)$, 农户受教育 程度主要为初中 (取值范围为 $0 \sim 15$, 文盲及半文盲、小学、初中、高中及中专、大专及以上各个教育水平分别 赋值 $0 、 6 、 9 、 12 、 15)$, 因此 $d_{\mathrm{age}}$ 和 $d_{\mathrm{edu}}$ 分别为 5 和 9. 另外, 参考杨顺顺等 ${ }^{[29]}$ 和李丽丽 ${ }^{[34]}$ 的设置, 利用模型进行 仿真模拟和调试, 确定公式 (1) 中 $\beta_{\mathrm{fe}} 、 \boldsymbol{\beta}_{\mathrm{pe}} \boldsymbol{\beta}_{\mathrm{fi}} 、 \beta_{\mathrm{ma}} \boldsymbol{\beta}_{\mathrm{ir}} \boldsymbol{\beta}_{\mathrm{lan}}$ 和 $\beta_{\mathrm{lab}}$ 分别为 $0.29 、 0.079 、 0.017 、 0.055 、 0.12 、 0.5$ 和 $0.1, \alpha_{0} 、 \alpha_{\text {ege }}$ 和 $\alpha_{\text {edu }}$ 分别为 $5.58 、 0.01$ 和 0.005. 最终反映珠江流域农作物生产的函数见公式 (2). 另外,在政策 情景分析初始步数调整过程中,利用 MAREM 模型对 2000-2012 年化肥施用强度、农药施用强度和畜禽养 殖户户数等模拟的过程中, 发现约至 100 期 ( 1 期相当于农户 1 次决策或者行动),模型生产要素投人模拟结 果达到珠江流域 2012 年真实历史水平; 本研究对 2013-2030 年珠江流域氮、磷营养盐在不同情景下的人河 量进行预测, 即政策模拟从 2013 年开始,相应地, MAREM 模型的政策模拟从 101 期开始; 而每一预测年所 对应期数依据 MAREM 模型在基准情景下化肥施用强度、农药施用强度和畜禽养殖户户数等模拟数据与 SD 仿真模型模拟 (基准情景) 的计算结果相一致, 然后再找出 MAREM 模型在其余 3 种情景下化肥施用强度、 农药施用强度和畜禽养殖户户数等模拟数据.

$$
Y_{\mathrm{vc}}=\mathrm{e}^{5.58+0.01 \times 5+0.005 \times 9} \cdot X_{\mathrm{fe}}^{0.29} \cdot X_{\mathrm{pe}}^{0.079} \cdot X_{\mathrm{fi}}^{0.017} \cdot X_{\mathrm{ma}}^{0.055} \cdot X_{\mathrm{ir}}^{0.12} \cdot X_{\mathrm{lan}}^{0.5} \cdot X_{\mathrm{lab}}^{0.11}
$$

1.1.2 模型有效性检验 模型有效性检验主要是检验模型的输人输出特征是否能符合其映射的现实世界实 相行为特征, 通常模型只要能够正确反映实相行为, 符合实际统计结果或调查结果则认为其是有效的 ${ }^{[29]}$. 本研究通过使用珠江流域 2000-2012 年的实际统计数据与模型模拟数据进行对比,讨论模型是否能够正确 反映历史变化规律来说明 C-D 生产函数和 MAREM 模型的有效性. 检验变量主要包括能够反映农户的农业 生产及要素投人以及生产选择决策的农作物生产量、农用化肥施用强度、农药使用强度、农用塑料薄膜使用 强度和农业机械总动力投入强度, 年平均相对误差分别为 $6.8 \% 、 0.4 \% 、 0.6 \% 、 0.3 \%$ 和 $0.3 \%$, 模拟效果较好. 此外, MAREM 模型在模拟养殖业生产时, 虚拟畜禽的平均利润波动幅度较大, 而随着农户进人养殖生产后, 养殖户户数增加, 畜禽养殖量增多, 每头畜禽的利润从较高的水平降到较低的水平进行波动, 由此 “蛛网效 应” 即周期性波动出现 (图 2). 由波动曲线可以进一步发现, 养殖农户户数的波动曲线明显滞后于畜禽利润 的波动曲线, 这是因为农户在判断当期的养殖生产行为时往往基于前期的畜禽利润, 当前期利润升高时, 养 殖户可能会增大养殖规模, 反之则会降低. 因此, 模拟结果能反映现实中畜禽价格易波动、养殖风险大以及 农户养殖行为滞后的特征. 当然, 当种植业成本增加时, 农户也可能由种植生产转向养殖生产. 故本研究校 正的 C-D 生产函数是一个能够很好地描述珠江流域农作物生产情况的函数, MAREM 模型进行政策情景模 拟后能够较好地输出生产数据从而作为农业污染子系统的输人数据.

\section{2 情景设定}

目前, 化肥、农药过度使用所带来农业非点源污染问题日趋严重, 中国政府为了遏制此现象, 国务院颁 发的《中华人民共和国增值税暂行条例》规定自 2009 年 1 月 1 日开始增收农药税,财政部、海关总署和国家 税务总局印发《关于对化肥恢复征收增值税政策的通知》规定自 2015 年 9 月 1 日起从新增收化肥税. 本研 究为甄别有效的农业税收政策来控制珠江流域营养盐污染, 设置 1 组基准情景以及 5 组政策情景 (共 20 种 


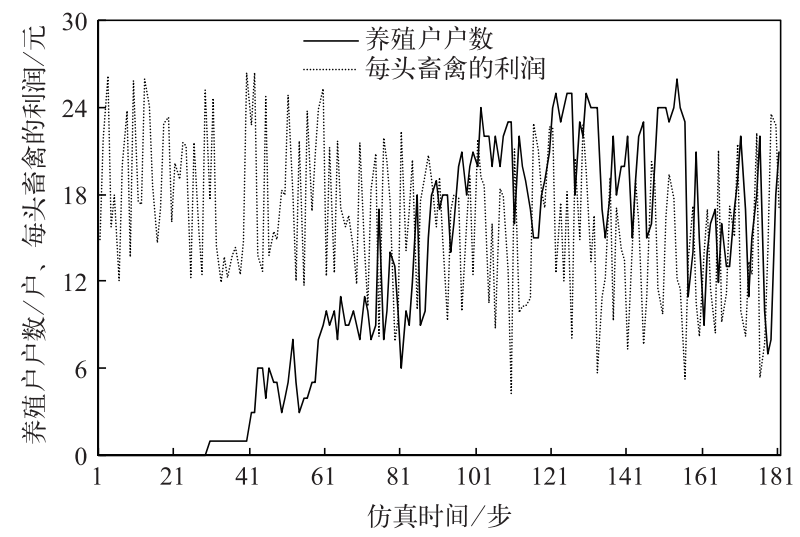

图 2 MAREM 模型中养殖户户数变化与虚拟畜禽利润波动的关系

Fig. 2 The relationship between animal raiser household and virtual animal profit in MAREM model

政策情景), 5 组政策情景均建立在基准情景上,每组情景均由化肥税和农药税组成,税率水平分为 5 类,分 别为 $0 \% 、 25 \% 、 50 \% 、 75 \%$ 和 $100 \%$, 考虑到高于 $100 \%$ 的税率将会给农户带来较大的经济负担,这里不考虑更 高的税率情景. 并且在每组情景中, 化肥税为主导政策,农药税为辅助政策. MAREM 模型的模拟结果 (表 1) 表明,在无控制政策干扰下 (基准情景),农户会继续增加化肥和农药投人; 相比于无政策干扰的对照方案

表 1 不同政策情景下 MAREM 模拟结果对比

Tab.1 The comparison of simulation results in MAREM model under various scenarios

\begin{tabular}{|c|c|c|c|c|c|c|c|c|c|}
\hline \multirow[b]{2}{*}{ 情景序号 } & \multirow[b]{2}{*}{ 情景编号 } & \multirow[b]{2}{*}{$\begin{array}{l}\text { 化肥税 } \\
\text { 税率/\% }\end{array}$} & \multirow[b]{2}{*}{$\begin{array}{l}\text { 农药税 } \\
\text { 税率/\% }\end{array}$} & \multicolumn{6}{|c|}{2030 年政策情景模拟数值及其相对基准情景的变化 } \\
\hline & & & & $\begin{array}{c}\text { 化肥投 } \\
\text { 人强度/ } \\
\left(\mathrm{kg} / \mathrm{hm}^{2}\right) \\
\end{array}$ & $\begin{array}{c}\text { 化肥投人强 } \\
\text { 度相对变化/ } \\
\%\end{array}$ & $\begin{array}{c}\text { 农药投 } \\
\text { 人强度/ } \\
\left(\mathrm{kg} / \mathrm{hm}^{2}\right)\end{array}$ & $\begin{array}{c}\text { 农药投人强 } \\
\text { 度相对变化/ } \\
\%\end{array}$ & $\begin{array}{c}\text { 种植业用地 } \\
\text { 相对变化 } \\
\%\end{array}$ & $\begin{array}{c}\text { 养殖户户数 } \\
\text { 相对变化 } \\
\%\end{array}$ \\
\hline 0 & 基准情景 & 0 & 0 & 1040.85 & - & 31.65 & - & - & - \\
\hline 1 & 组别一 & 25 & 0 & 783.60 & -24.72 & 28.50 & -9.83 & -1.27 & 16.93 \\
\hline 2 & 组别一 & 50 & 0 & 623.10 & -40.13 & 25.95 & -17.66 & -1.26 & 18.17 \\
\hline 3 & 组别一 & 75 & 0 & 511.95 & -50.82 & 24.45 & -22.79 & -1.08 & 16.19 \\
\hline 4 & 组别一 & 100 & 0 & 446.40 & -57.11 & 22.95 & -27.26 & -2.00 & 22.15 \\
\hline 5 & 组别二 & 25 & 25 & 771.75 & -25.86 & 22.05 & -30.20 & -0.32 & 6.23 \\
\hline 6 & 组别二 & 50 & 25 & 607.80 & -41.61 & 20.40 & -35.38 & -0.43 & 7.98 \\
\hline 7 & 组别二 & 75 & 25 & 501.00 & -51.86 & 18.90 & -39.98 & -1.47 & 14.85 \\
\hline 8 & 组别二 & 100 & 25 & 432.15 & -58.48 & 17.85 & -43.30 & -4.71 & 47.77 \\
\hline 9 & 组别三 & 25 & 50 & 753.90 & -27.57 & 18.00 & -42.88 & -1.37 & 21.19 \\
\hline 10 & 组别三 & 50 & 50 & 595.65 & -42.77 & 16.50 & -47.63 & -2.09 & 30.31 \\
\hline 11 & 组别三 & 75 & 50 & 494.10 & -52.53 & 15.45 & -51.14 & -2.17 & 24.96 \\
\hline 12 & 组别三 & 100 & 50 & 424.05 & -59.25 & 14.70 & -53.51 & -3.19 & 33.72 \\
\hline 13 & 组别四 & 25 & 75 & 745.65 & -28.36 & 15.30 & -51.80 & -0.51 & 7.11 \\
\hline 14 & 组别四 & 50 & 75 & 586.50 & -43.65 & 13.95 & -55.75 & -1.74 & 20.80 \\
\hline 15 & 组别四 & 75 & 75 & 486.75 & -53.24 & 13.05 & -58.59 & -1.71 & 16.72 \\
\hline 16 & 组别四 & 100 & 75 & 419.25 & -59.73 & 12.30 & -61.06 & -3.80 & 38.02 \\
\hline 17 & 组别五 & 25 & 100 & 738.15 & -29.08 & 13.05 & -58.59 & -0.69 & 11.23 \\
\hline 18 & 组别五 & 50 & 100 & 580.95 & -44.18 & 12.00 & -61.82 & -1.79 & 21.64 \\
\hline 19 & 组别五 & 75 & 100 & 485.70 & -53.33 & 11.40 & -64.10 & -3.54 & 35.72 \\
\hline 20 & 组别五 & 100 & 100 & 412.05 & -60.41 & 10.50 & -66.62 & -6.74 & 69.53 \\
\hline
\end{tabular}


(基准情景), 实施化肥税可以降低农户的化肥投人强度, 实施农药税可以降低农户的农药施用强度; 税率不 同,税收政策的实施效果不同; 从实施化肥税和农药税对化肥和农药投人水平的影响来看,相同农药税税率 下, 化肥和农药投人强度均随着化肥税税率增大而减小; 相同化肥税税率下, 化肥和农药投人强度均随着农 药税税率增大而减小; 如果实施化肥税的同时实施农药税, 能够间接增强对化肥投人强度的控制效果. 在实 施不同税率水平的化肥税和农药税后, 人工村落中种植业用地普遍降低, 养殖户户数普遍增加, 也就是税收 政策虽然控制了化肥和农药的过量使用, 但是可能导致部分农田被闲置, 并促使农户转向养殖生产转移或 外出就业.

本研究基于生产成本压力小、化肥控制效果显著、考虑其他税收的辅助作用和污染总量小的原则, 采用 化肥税和农药税两种农业政策组合 (重点关注化肥税对珠江流域营养盐污染控制的效果, 同时考虑农药税 对化肥施用可能产生的影响), 设计了基准情景(社会经济按照历史水平和规划发展, $0 \%$ 化肥税税率和 $0 \%$ 农药税税率)、低化肥税情景 ( $25 \%$ 化肥税税率和 $25 \%$ 农药税税率, 情景一) 、中化肥税情景 ( $50 \%$ 化肥税税率 和 $25 \%$ 农药税税率, 情景二) 和高化肥税情景 (75\%化肥税税率和 25\% 农药税税率, 情景三) 4 种具有代表性 的情景方案, 情景一、二和三均建立在基准情景的基础上, 通过将 MAREM 模型输出结果输人到珠江流域营 养盐 SD 仿真系统, 对比分析探求珠江流域营养盐控制的最佳农业政策组合情景模式. 在本研究情景分析 中, MAREM 模型每一个仿真周期, 农户将根据其资金情况和上一周期市场农作物和畜禽价格决定其在本周 期进行种植业生产或养殖业生产,假设 4 种情景相同年份农作物单价和畜禽单价不变; 税率指税收占化肥 或农药销售价格的比例.

\section{2 结果与分析}

\section{1 农业生产及要素投入分析}

本研究在不同农业政策情景下对珠江流域农业生产及要素投人情况进行了模拟 (图 3). 情景一、情景 二和情景三均相对基准情景有效地控制了化肥施用 (折纯) 量, 年均降低幅度分别为 $16.1 \%$ 、 $26.9 \%$ 和 $33.2 \%$; 其中, 情景一的化肥施用量以 $0.8 \%$ 年均增长速度逐年递增, 情景二和情景三分别以 $0.6 \%$ 和 $1.7 \%$ 年均降低 速度整体呈递减趋势且在 2025 年后趋于平稳. 本研究依据调研数据, 按照珠江流域每年两季种植次数计 算, 且在贾仁安等的研究中发现, 要达到 $9000 \sim 12000 \mathrm{~kg} / \mathrm{hm}^{2}$ 的粮食产量, 并保持和提高土壤肥力, 合理的施 肥量中纯氮为每季施 $150 \sim 180 \mathrm{~kg} / \mathrm{hm}^{2}$, 纯磷为每季施 $45 \sim 75 \mathrm{~kg} / \mathrm{hm}^{2[35]}$, 则珠江流域每年纯氮和纯磷肥料施 用上限标准分别为 360 和 $150 \mathrm{~kg} / \mathrm{hm}^{2}$. 基准情景中, 珠江流域 2016 年氮肥施用强度和 2020 年磷肥施用强度 开始超过标准, 并将于 2030 年均达到标准值的 1.4 倍; 情景一中, 氮肥施用强度和磷肥施用强度分别在 2025 年和 2027 年开始超过标准, 2025 年后肥料施用量的增长趋于平缓, 尽管未来肥料施用强度仍然有所增长, 但增长幅度较小; 情景二和情景三的氮肥和磷肥施用强度则始终低于标准值, 前者 2013-2030 年氮肥和磷 肥施用强度范围分别为 292.9 328.5 和 106.2 125.4 kg/ $\mathrm{hm}^{2}$, 后者 2013-2030 年氮肥和磷肥施用强度范围 分别为 $243.9 \sim 328.1$ 和 $97.5 \sim 108.6 \mathrm{~kg} / \mathrm{hm}^{2}$. 除了肥料施用量得到控制外, 情景一、情景二和情景三中农药施 用量均大幅度下降, $2013-2030$ 年下降幅度范围分别为 $0.3 \% \sim 27.6 \% 、 0.3 \% \sim 32.8 \%$ 和 $0.3 \% \sim 37.4 \%$, 尽管 以上 3 种情景所实施的农药税税率均为 $25 \%$, 但随着化肥税税率的提高, 农药税对农药施用量的控制作用 也逐渐增强.

随着化肥和农药两个重要生产要素投人的减少, 珠江流域农作物生产量也出现不同程度的降低. 在变 化趋势上, 情景一呈缓慢上升并趋于平缓的趋势, 情景二和情景三均呈缓慢下降并趋于平缓的趋势, 年均降 低幅度分别为 $6.8 \% 、 11.0 \%$ 和 $13.7 \%$. 然而, 在化肥税和农药税影响下珠江流域畜禽养殖量有所提高(本研究 将畜禽养殖量统一换算成猪的养殖当量), 相比于基准情景, 情景一、情景二和情景三增幅逐渐增大, 20132030 年平均增幅分别为 $3.0 \% 、 3.8 \%$ 和 7.0\% . 然而, 农作物生产量和畜禽养殖量的变化幅度均随着化肥税税 率的提高而增强,这些结果说明税收政策能够改变和调整农业产业结构.

\section{2 氮、磷营养盐污染情景分析}

从氮、磷营养盐人河量来看, 政策情景具有明显的控制效果 (图 4). 2030 年, 基准情景、情景一、情景二 和情景三的总氮 $(\mathrm{TN})$ 人河量分别为 $94.5 、 85.1 、 78.5$ 和 75.3 万 $\mathrm{t}$; 总磷 ( TP ) 人河量分别为 $14.0 、 12.8 、 12.0$ 和 

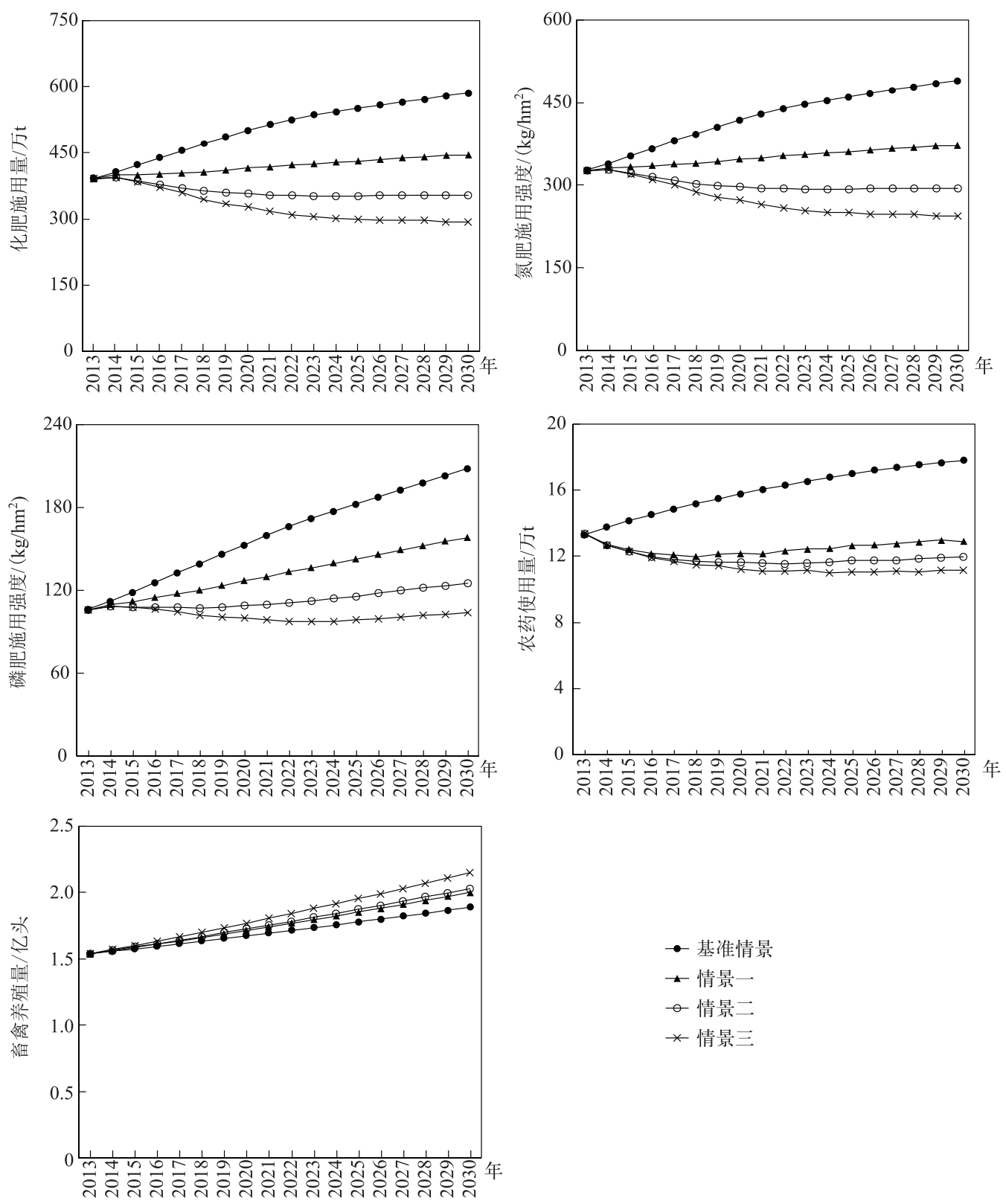

- - 基准情景

—情景

— 情景二

* 情景三

图 3 不同情景下珠江流域农业生产及要素投入的变化趋势

Fig.3 Temporal trend for agricultural production and elements input in Pearl River Basin under various scenarios

11.6 万 t. 情景一、情景二和情景三的 2013-2030 年 TN 人河量分别在 2026、2024 和 2015 年出现最高值, 相 对于基准情景,年均减少幅度分别为 6.4\%、10.9\% 和 $12.9 \%$. 对于 2013-2030 年 TP 人河量,情景一、情景二和 情景三都显示先增加后趋于平缓的趋势,年均增长速度分别为 $0.9 \% 、 0.5 \%$ 和 $0.3 \%$,相对于基准情景 ( $1.4 \%$ ) 都 较小. 在 TN 人河量中, 2013-2030 年期间, 仅在 2021-2025 年(情景二) 和 2019-2030 年 (情景三), 城镇 污水为首要污染源, 其次是种植业、养殖业和农村污水; 在基准情景、情景一、情景二和情景三的其余年份, 种植业对 TN 人河量贡献最多, 其次是城镇污水、养殖业和农村污水. 在 TP 人河量中, 仅在 2018-2030 年 (情景三), 养殖业为首要污染源, 其次是种植业、城镇污水和农村污水; 在基准情景、情景一、情景二和情景 
三的其余年份, 种植业对 TP 人河量贡献最多, 其次是养殖业、城镇污水和农村污水. 总之, 化肥税和农药税 的组合型政策能够有效减少氮、磷营养盐污染量, 且营养盐污染削减量还随着政策税率的提高而提高.
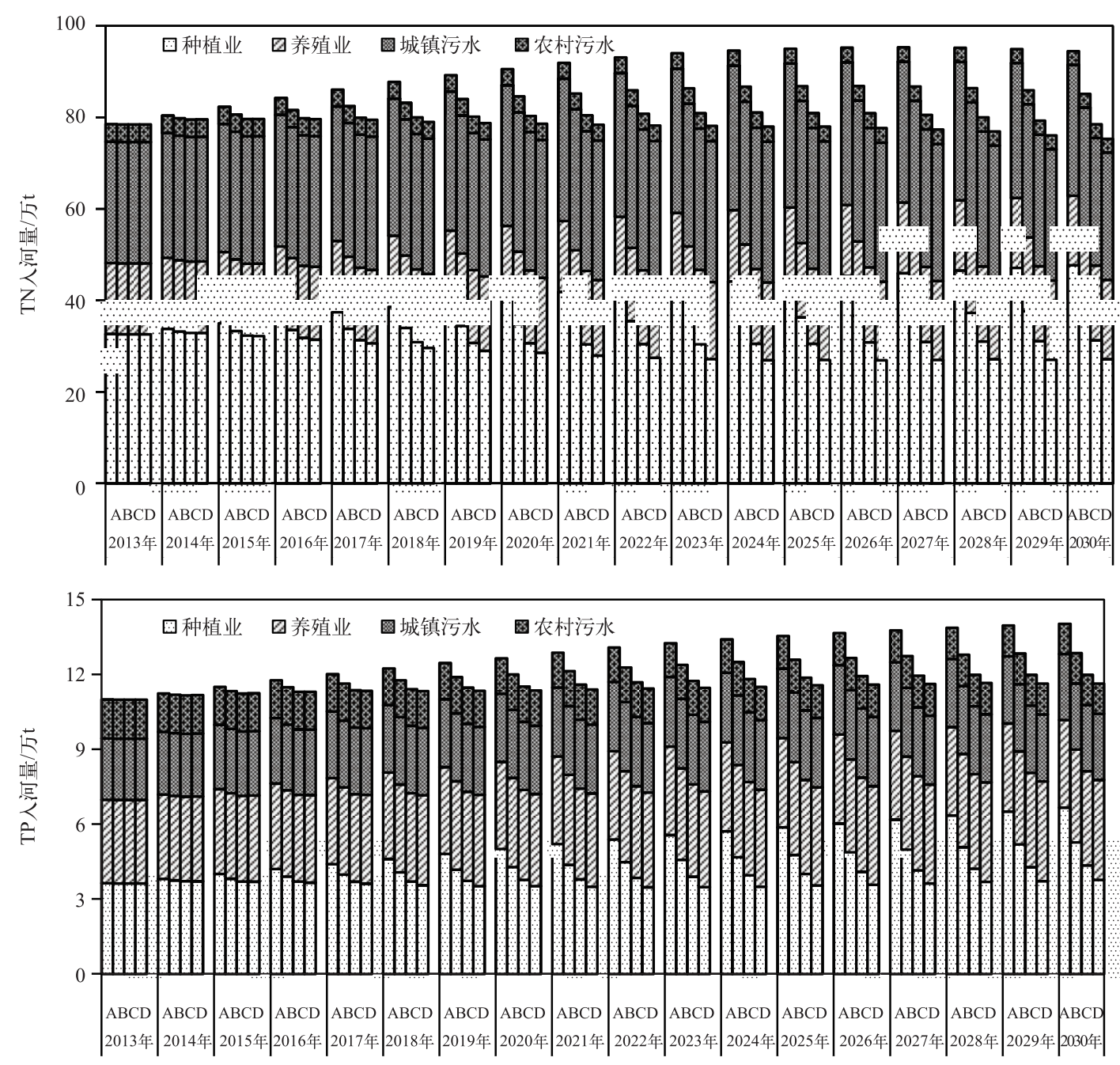

图 4 不同情景下珠江流域营养盐来源及人河量的时间变化趋势

( $A 、 B 、 C$ 和 $D$ 分别代表基准情景、情景一、情景二和情景三,下同)

Fig.4 Source and temporal trend for TN and TP inputs in Pearl River Basin under various scenarios ( A, B, C and D stand for business-as-usual scenario, scenario 1 , scenario 2 and scenario 3 , respectively, the same below)

种植业作为珠江流域营养盐污染的最大贡献源, 在政策情景下, 它对总污染量的贡献率大幅度下降, 在 情景三中,从 2019 年开始低于城镇污水的贡献率. 在 2030 年,情景一、情景二和情景三中种植业的 TN 人河 量分别为 37.8 、31.2 和 27.1 万 $\mathrm{t}$, 贡献率分别为 $44.4 \% 、 39.8 \%$ 和 $36.0 \%$, 人河量相对于基准情景分别减少 $20.7 \% 、 34.5 \%$ 和 $43.1 \%$; 种植业的 TP 人河量分别为 $5.3 、 4.4$ 和 3.8 万 $\mathrm{t}$, 贡献率分别为 $41.1 \% 、 36.3 \%$ 和 $32.4 \%$, 人河量相对于基准情景分别减少 $20.9 \% 、 34.7 \%$ 和 $43.4 \%$.

养殖业是农业生产系统的另一个重要污染源, 相比基准情景, 它在政策情景模拟中产生更多的污染量, 并且随着化肥税升高, 氮、磷营养盐人河量逐渐增大. 在情景一中, 养殖业的 TN 人河量在 2025 年达到最大 值 (16.3 万 $\mathrm{t}$ ) ; 情景二中, 养殖业的 TN 人河量出现先上升, 接着几乎持平 (2025-2027 年), 后下降的趋势; 
情景三则出现一直上升的趋势, 年均增长率为 $0.7 \%, 2030$ 年达到 17.4 万 $\mathrm{t}$. 对于养殖业 TP 人河量, 情景一、 情景二和情景三逐年增加,2030 年相对于基准情景 (3.5 万 $\mathrm{t}$ ) 分别增加 5.9\%、7.6\% 和 14.0\%. 基准情景下养 殖业产生的氮、磷营养盐污染将会逐渐减少, 这是因为集约化的养殖业发展使得畜禽污染处理变得集中化 和可控化, 由此较多的污染得到削减; 然而, 3 种情景下每年的养殖业 TN 和 TP 人河量均大于基准情景, 主 要是由于在政策情景下,更多的农户从种植生产转向养殖生产.

\section{3 主要污染源解析}

种植业营养盐污染源主要是化肥、有机肥和农作物残体(图 5). 2030 年情景一、情景二和情景三的氮施 用量相对基准情景分别降低了 $20.7 \% 、 34.4 \%$ 和 43.1\%, 磷施用量分别降低了 $20.8 \% 、 34.7 \%$ 和 43.4\%, 政策情 景的营养要素投人减少是农作物减产的真正原因. 对于种植业氮施用量, 在情景一、情景二和情景三中, 2013-2030 年化学氮肥施用 (折纯) 量对种植业的贡献均出现逐年下降的趋势, 年均贡献率分别为 $84.0 \%$ 、 $82.0 \%$ 和 $80.0 \%$, 相对于基准情景分别减少 $2.6 \% 、 4.9 \%$ 和 $7.1 \%$; 有机氮施用量对种植业的贡献均出现逐年上 升的趋势, 年均贡献率分别为 $11.0 \% 、 12.6 \%$ 和 $14.2 \%$, 均高于基准情景年均贡献率 $(9.1 \%)$; 农作物残体污染 量的贡献率均逐年上升, 年均贡献率相比基准情景 ( 4.6\%) 分别上升 $8.4 \% 、 17.0 \%$ 和 $22.8 \%$. 而对于种植业磷 施用量, 在情景一、情景二和情景三中, 2013-2030 年化学磷肥施用 (折纯) 量的贡献最大, 到达 2030 年施用 量分别为 89.0 、70.6 和 58.4 万 $\mathrm{t}$, 年平均贡献率分别为 $83.7 \% 、 81.6 \%$ 和 $79.7 \%$, 均低于基准情景 $(85.9 \%$ ); 有 机磷施用量的年均贡献率相对于基准情景 (10.5\% ) 分别上升 19.1\%、35.9\% 和 52.5\%,3 种情景的施用量均 上升; 而农作物残体污染量的年均贡献率相对于基准情景 (3.6\%) 分别上升 8.0\%、16.2\% 和 $21.7 \%$, 情景一农 作物残体污染量呈现上升趋势, 2030 年情景二农作物残体污染量基本与 2013 年持平, 情景三呈现下降趋
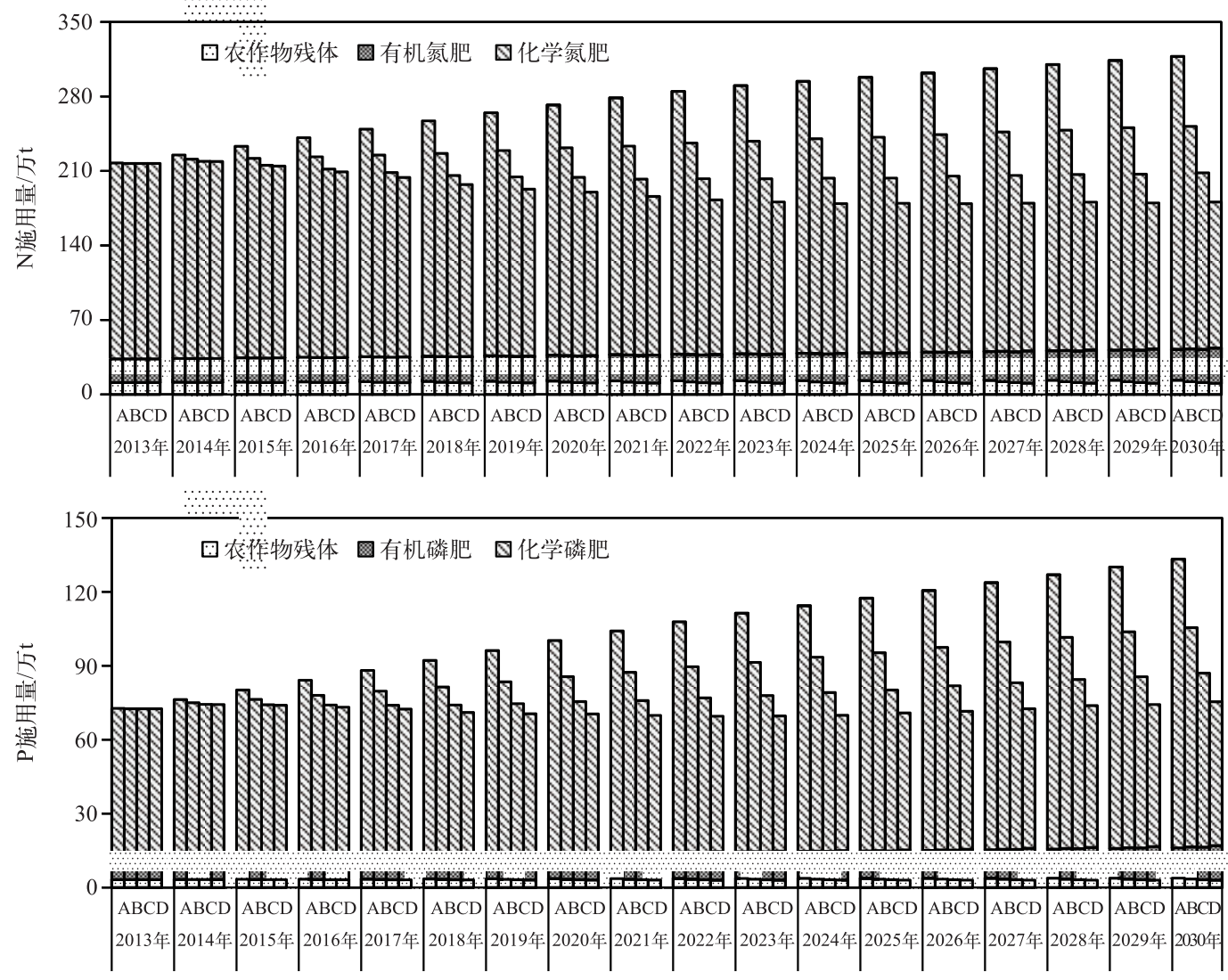

图 5 不同情景下种植业 $\mathrm{N}$ 和 $\mathrm{P}$ 施用量的时间变化趋势

Fig.5 Temporal trend for quality of $\mathrm{N}$ and $\mathrm{P}$ applied in planting industry under various scenarios 
势. 在所有情景中,农作物残体所占的比重最小, 它的污染量与农作物产量呈正比,受秸秆处理方式影响. 随 着农业化肥税的提高, 化肥施用量降低; 而化肥施用量的减少必然会导致农作物减产, 未来如果要在降低化 肥施用量的同时还保持较高的农作物产量, 则需要施用更多的有机肥料来满足农作物生长的需求. 尽管税 收政策对于推动有机肥的使用有一定的效果,但施用量仍然较低, 对农作物营养要素补充不足, 使得农作物 减产现象仍然无法避免,因此未来还需要结合补贴等政策来快速推动农户对有机肥的使用.

而对于畜禽养殖业, 本研究对储存和堆肥、直排以及深度处理 3 个过程后流失的 TN 和 TP 人河量进行 了分析 (图 6). 对于 TN 人河量, 最大贡献源为处理后 TN 流失, 依次是直排 TN 流失和储存和堆肥过程 TN 流失; 至 2016 年, 处理后 TN 流失贡献比例开始大于直排 TN 流失. 2013-2030 年基准情景、情景一、情景二 和情景三的储存和堆肥过程 TN 流失均出现逐年上升趋势, 年均增长率分别为 $1.0 \% 、 1.3 \% 、 1.4 \%$ 和 $1.8 \%$; 2013-2030 年基准情景、情景一、情景二和情景三的直排 TN 流失均出现逐年下降的趋势, 年均下降率分别 为 $2.2 \% 、 1.8 \% 、 1.8 \%$ 和 $1.4 \%$; 对于处理后 $\mathrm{TN}$ 流失, 基准情景至 2028 年达到最大值 ( 7.2 万 $\mathrm{t}$ ), 情景一、情景 二和情景三逐年上升, 年均增长率分别为 $1.4 \% 、 1.5 \%$ 和 $1.9 \%$. 而对于 TP 人河量, 最大贡献源为处理后 TP 流失, 依次是直排 TP 流失以及储存和堆肥过程 TP 流失. 储存和堆肥过程 TP 流失, 2013-2030 年基准情 景、情景一、情景二和情景三均出现逐年上升的趋势, 年均增长率分别为 $1.0 \% 、 1.3 \% 、 1.4 \%$ 和 $1.8 \%$; 20132030 年基准情景、情景一、情景二和情景三的直排 TP 流失均出现逐年下降的趋势, 年均下降率分别为 $2.1 \% 、 1.8 \% 、 1.7 \%$ 和 $1.4 \%$; 对于处理后 TP 流失, 基准情景和情景一分别在 2026 年 ( 2.2 万 $\mathrm{t}$ ) 和 2029 年 (2.3 万 $\mathrm{t}$ ) 达到最大值, 情景二和情景三逐年上升, 年均增长率分别为 $1.5 \%$ 和 $1.9 \%$. 总之, 关于畜昺 TN/TP 污染 量和畜禽养殖量的增加, 在相同税收政策控制下, 畜禽养殖人河量与畜禽养殖量增加比例相同, 经过不同流 失过程产生的畜禽污染量也与对应情景的畜禽养殖量呈正比例增加. 此外, 若在政策情景中保持原来的发
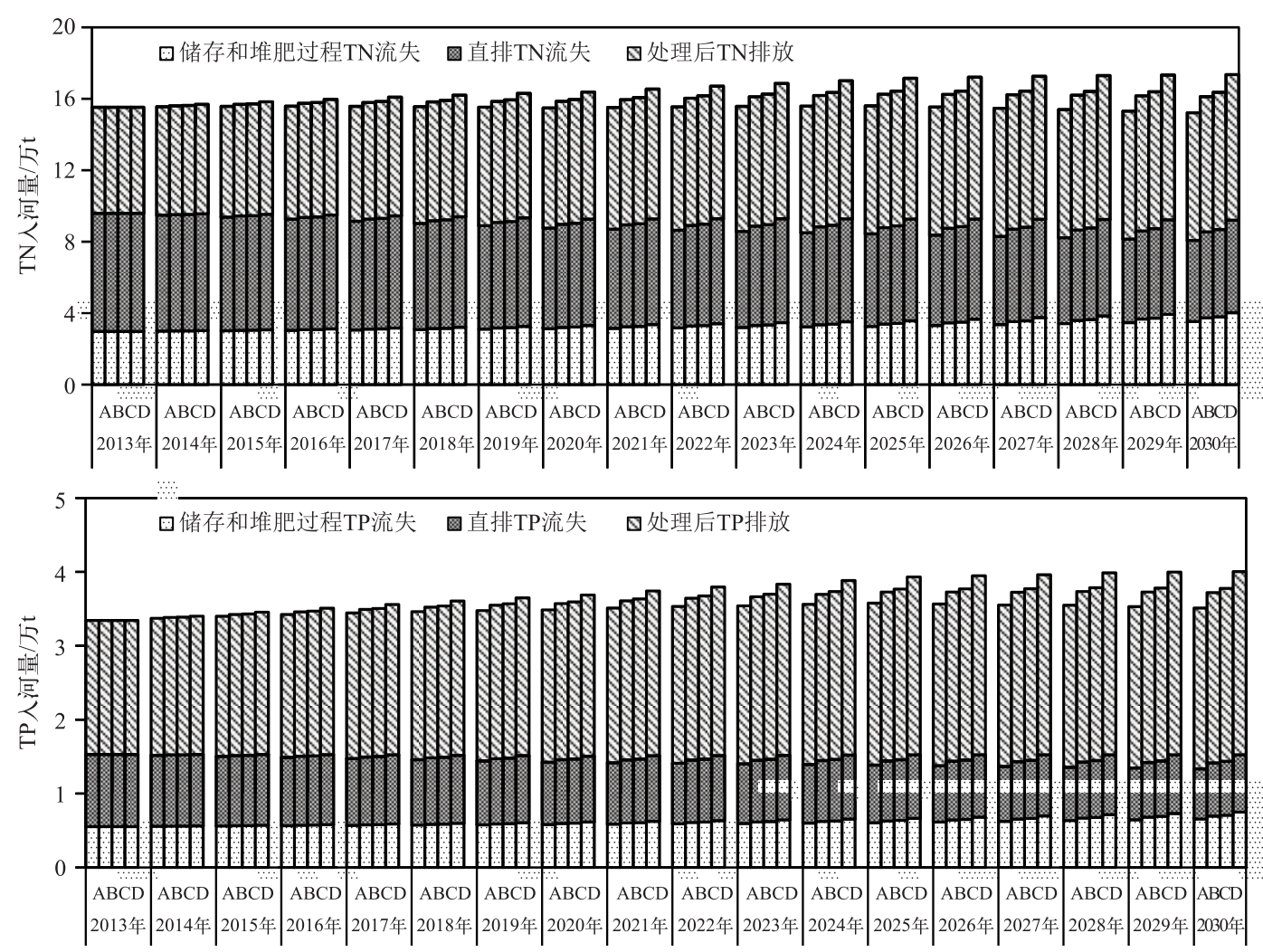

图 6 不同情景下畜禽养殖业 TN 和 TP 人河量的时间变化趋势

Fig.6 Temporal trend for TN and TP inputs in livestock and poultry breeding under various scenarios 
展速度来推广沼气工程等畜禽粪污无害化处理和利用方式以及建设畜禽污水集中处理设施, 那未来畜禽养 殖营养盐污染的增长速度也将逐渐变缓,而且能够较快达到平缓增长状态.

在情景一、情景二和情景三中, 城镇污水和农村生活污水所产生的营养盐人河量与基准情景相比变化 不大 (图 4), 这是因为化肥税和农药税的直接调控对象是农业生产子系统, 而其他系统受到的影响则间接通 过农业生产系统起作用. 尤其对于城镇污水, 其产生量受到城镇居民污染物产生水平和人口数量的影响, 但 污染物产生水平与整体经济发展水平相关, 整体经济发展水平越高, 城镇居民生活污染物产生水平也越高, 此外,农业结构调整对未来经济整体发展影响较弱, 进而城镇居民污染物产生水平受到的影响也较小.

总之,化肥税和农药税的组合型政策对农业营养盐污染控制具有较强的针对性,而且还能兼顾经济的 平衡发展. 三种情景都能够有效减少营养盐污染量, 然而, 情景二和情景三比情景一的边际效果小、经济成 本高、农作物产出低和畜禽污染高,故情景一被认为是控制珠江流域营养盐污染的最优方案.

\section{3 结论与展望}

本研究在不同农业政策情景下对珠江流域模拟结果显示: 从农业投人和产出的角度看,随着化肥税税 率水平的提高, 化肥和农药的使用量不断减少, 农作物产量不断降低, 而畜禽养殖量增多, 过高的税率水平 可能会引起粮食安全问题以及增加畜禽养殖污染量. 2030 年, 基准情景、情景一、情景二和情景三的 TN 人 河量分别达到 $94.5 、 85.1$ 、78.5 和 75.3 万 t, TP 人河量分别达到 $14.0 、 12.8 、 12.0$ 和 11.6 万 t. 在 TN 人河总量 中, 2013-2030 年期间, 仅在 2021-2025 年 (情景二) 和 2019-2030 年(情景三), 城镇污水为首要污染源, 其次是种植业、养殖业和农村污水; 在基准情景、情景一、情景二和情景三的其余年份, 种植业对 TN 人河量 贡献最多, 其次是城镇污水、养殖业和农村污水. 在 TP 人河总量中, 仅在 2018-2030 年 (情景三), 养殖业为 首要污染源, 其次是种植业、城镇污水和农村污水; 在基准情景、情景一、情景二和情景三其余年份, 种植业 TP 人河量贡献最多,其次是养殖业、城镇污水和农村污水.

化肥税和农药税的组合型政策能够有效减少营养盐污染量, 然而, 情景二和情景三比情景一的边际效 果小、经济成本高、农作物产出低和畜禽污染高, 故情景一是本研究中控制珠江流域营养盐污染的最优方案. 但是, 在耦合 SD 模型和 MAREM 模型进行政策情景分析时, 主要关注税收政策 (如化肥税和农药税) 的环境 影响, 而税收会造成农户生产成本增加, 降低农业发展和改造的积极性, 并进一步影响到粮食安全. 因此, 建 议今后在技术层面上应引导农户精准施肥和施高效肥, 加快对畜禽养殖污染治理技术和低毒高效农药等的 研究开发和推广使用; 在多目标情景下, 设计并模拟更多的政策情景, 如环境保护补贴政策情景、土地制度 改革政策情景和环境服务付费情景, 继续探索基于农户个体行为的流域营养盐污染控制政策选择.

\section{4 参考文献}

[ 1 ] Strokal M, Yang H, Zhang YC et al. Increasing eutrophication in the coastal seas of China from 1970 to 2050. Marine Pollution Bulletin, 2014, 85(1) : 123-140.

[ 2 ] Qu HJ, Kroeze C. Past and future trends in nutrients export by rivers to the coastal waters of China. Science of the Total Environment, 2010, 408(9): 2075-2086.

[ 3 ] Wu ZY, Saito Y, Zhao DN et al. Impact of human activities on subaqueous topographic change in Lingding Bay of the Pearl River estuary, China, during 1955-2013. Scientific Reports, 2016, 6: 37742.

[ 4 ] Jiang T, Li K, Ke D. On the water environmental pollution and protection measures in the Guangzhou section of Pearl River. J Lake Sci, 2004, 16(3) : 282-284. DOI:10.18307/2004.0315. [江涛, 黎坤, 柯栋. 珠江广州段水环境问题与保 护对策. 湖泊科学, 2004, 16(3): 282-284.]

[ 5 ] Meng W, Zhang Y, Wang XQ et al. Study on technique of basin water-quality target management ( V ) : Economic policies for water pollution control. Research of Environmental Sciences, 2008, 21(4): 1-9. [孟伟, 张远, 王西琴等. 流域水 质目标管理技术研究: V.水污染防治的环境经济政策. 环境科学研究, 2008, 21(4) : 1-9.]

[ 6 ] Yang SS, Qu HJ, Luan SJ et al. Environmental implications of rural policies in China: A multi-agent model at the level of agricultural households. Journal of Integrative Environmental Sciences, 2014, 11(1) : 17-37.

[ 7 ] Hao FH, Cheng HG, Yang ST eds. Theory and application of non-point source pollution modeling. Beijing: China Envi- 
ronmental Science Press, 2006: 445. [郝芳华, 程红光, 杨胜天. 非点源污染模型一一理论方法与应用. 北京: 中国 环境科学出版社, 2006: 445.]

[ 8 ] Qu HJ, Kroeze C. Past and future trends in nutrients export by rivers to the coastal waters of China. Science of the Total Environment, 2010, 408(9) : 2075-2086.

[ 9 ] Ti CP, Yan XY. Spatial and temporal variations of river nitrogen exports from major basins in China. Environmental Science and Pollution Research, 2013, 20(9): 6509-6520.

[10] Wu YP, Chen J. Investigating the effects of point source and nonpoint source pollution on the water quality of the East River (Dongjiang) in South China. Ecological Indicators, 2013, 32: 294-304.

[11] Guo WX, Fu YC, Ruan BQ et al. Agricultural non-point source pollution in the Yongding River Basin. Ecological Indicators, 2014, 36: 254-261.

[12] Gao B, Yan XY, Jiang XS et al. Research progress in estimation of agricultural sources pollution of the Lake Taihu region. J Lake Sci, 2014, 26(6) : 822-828. DOI: 10.18307/2014.0602. [高波, 颜晓元, 姜小三等. 太湖地区农业源污染核 算研究进展. 湖泊科学, 2014, 26(6): 822-828.]

[13] Bouwman AF, Beusen AHW, Billen G. Human alteration of the global nitrogen and phosphorus soil balances for the period 1970-2050. Global Biogeochemical Cycles, 2009, 23(4) : 1-16.

[14] VanDrecht G, Bouwman AF, Harrison J et al. Global nitrogen and phosphate in urban wastewater for the period 1970 to 2050. Global Biogeochemical Cycles, 2009, 23 (4) : GBOA03. DOI: 10.1029/2009GB003458.

[15] Thieu V, Mayorga E, Billen G et al. Subregional and downscaled global scenarios of nutrient transfer in river basins: Seine-Somme-Scheldt case study. Global Biogeochemical Cycles, 2010, 24: GB0A10.

[16] Yan WJ, Mayorga E, Li XY et al. Increasing anthropogenic nitrogen inputs and riverine DIN exports from the Changjiang River basin under changing human pressures. Global Biogeochemical Cycles, 2010, 24: GB0A06.

[17] Zinia NJ, Kroeze C. Future trends in urbanization and coastal water pollution in the Bay of Bengal: The lived experience. Environment, Development and Sustainability, 2015, 17(3) : 531-546.

[18] Wang HL, Wu ZN, Hu CH et al. Water and nonpoint source pollution estimation in the watershed with limited data availability based on hydrological simulation and regression model. Environmental Science and Pollution Research, 2015, 22 (18) : 14095-14103.

[19] Que Z, Seidou O, Droste RL et al. Using AnnAGNPS to predict the effects of tile drainage control on nutrient and sediment loads for a River Basin. Journal of Environmental Quality, 2015, 44(2) : 629-641.

[20] Shen ZY, Zhong YC, Huang Q et al. Identifying non-point source priority management areas in watersheds with multiple functional zones. Water Research, 2015, 68: 563-571.

[21] Li S, Zhang ZL, Sun YY. Simulation of non-point source pollution of nitrogen and phosphorus in Lake Nansi watershed using SWAT model. J Lake Sci, 2013, 25(2): 236-242. DOI: 10.18307/2013.0209. [李爽, 张祖陆, 孙媛媛. 基于 SWAT 模型的南四湖流域非点源氮磷污染模拟. 湖泊科学, 2013, 25(2): 236-242.]

[22] Rougoor CW, Van Zeijts H, Hofreither MF et al. Experiences with fertilizer taxes in Europe. Journal of Environmental Planning and Management, 2001, 44(6): 877-887.

[23] Chang WN, Parsche R, Radulescu DM et al. Taxation of fertilizers, pesticides and energy use for agricultural production in selected EU countries. European Environment, 2007, 17(4) : 267-284.

[24] Larson DM, Helfand GE, House BW. Second-best tax policies to reduce nonpoint source pollution. American Journal of Agricultural Economics, 1996, 78(4): 1108-1117.

[25] Falconer KE. Managing diffuse environmental contamination from agricultural pesticides: An economic perspective on issues and policy options, with particular reference to Europe. Agriculture, Ecosystems \& Environment, 1998, 69(1): 37-54.

[26] Soderholm P, Christiernsson A. Policy effectiveness and acceptance in the taxation of environmentally damaging chemical compounds. Environmental Science \& Policy, 2008, 11(3) : 240-252.

[27] Ju XT, Gu BJ, Wu YY et al. Reducing China's fertilizer use by increasing farm size. Global Environmental Change, 2016, 41: 26-32.

[28] Xu P, Lin YH, Yang SS et al. Input load to river and future projection for nitrogen and phosphorous nutrient controlling of Pearl River Basin. J Lake Sci, 2017, 29(6) : 1359-1371. DOI: 10.18307/2017.0608. [徐鹏, 林永红, 杨顺顺等. 珠江 
流域氮、磷营养盐人河量估算及预测. 湖泊科学, 2017, 29(6) : 1359-1371.]

[29] Yang SS, Luan SJ eds. Rural environmental management simulation based on the analysis of agricultural households' behavior. Beijing: Science Press, 2012: 201. [杨顺顺, 奕胜基. 农村环境管理模拟:农户行为的仿真分析. 北京: 科学出 版社, 2012: 201.]

[30] Li LL, Hu X, Yang SS et al. Evolutionary game analysis on environmental cooperation of rural households. Acta Scientiarum Naturalium Universitatis Pekinensis, 2014, 50(5) : 935-941. [李丽丽, 胡璇, 杨顺顺等. 农户环保合作的演化博 弯分析. 北京大学学报: 自然科学版, 2014, 50(5) : 935-941.]

[31] Yang SS, Luan SJ. Construction of rural environment multi-agent simulation system: Application of agricultural household model on rural environmental management. Acta Scientiarum Naturalium Universitatis Pekinensis, 2010, 46(1) : 129-135. [杨顺顺, 奕胜基. 农村环境多主体仿真系统建构——农户模型在农村环境管理中的应用. 北京大学学报: 自然 科学版, 2010, 46(1): 129-135.]

[32] Gao W. Agri-environmental policy assessment method research based on farm household scale [Dissertation]. Beijing: Peking University, 2015. [ 高薇. 基于农户尺度的农业环境政策评估方法研究 [学位论文]. 北京: 北京大学, 2015.]

[33] Wang L. Research on agriculture inland phenomenon under environmental and resource restriction [Dissertation]. Beijing: Peking University, 2015. [汪岗. 我国农业内陆化现象研究——基于资源环境视角 [学位论文]. 北京: 北京大 学, 2015.]

[34] Li LL. Simulation of nutrients export by rivers from watersheds and management policy scenario analysis: Case study of a Pearl River Sub-basin [Dissertation]. Beijing: Peking University, 2014. [李丽丽. 流域营养盐输出模拟及控制政策情 景分析一一珠江支流为例 [学位论文]. 北京: 北京大学, 2014.]

[35] Jia RA, Wang CX, Tu GP et al eds. System dynamic feedback hierarchy complexity analyze of scale livestock breeding ecology energy engineering. Beijing: Science Press, 2007: 319. [贾仁安, 王翠霞, 涂国平等. 规模养种生态能源工程 反馈动态复杂性分析. 北京: 科学出版社, 2007: 319.] 